\title{
Salinity Slows Germination of Rough Bluegrass
}

\author{
James J. Camberato ${ }^{1}$ and S. Bruce Martin ${ }^{2}$ \\ Clemson University, Pee Dee Research and Education Center, 2200 Pocket \\ Road, Florence, SC 29506
}

Additional index words. Cynodon sp., Poa trivialis, overseeding

\begin{abstract}
Bermudagrass (Cynodon sp.) greens are overseeded annually with rough bluegrass (Poa trivialis L.) in the coastal southeastern United States, where irrigation water is often saline. Salinity may slow seed germination and delay turf establishment. Cultivar and seed lot differences in sensitivity to salinity may be substantial. Our objective was to determine the effects of salinity on germination of commercially available rough bluegrass cultivars and seed lots. To accomplish this, we examined the effects of salinity $(0$, 1.8, 3.4, and 5.0 dS·m ${ }^{-1}$ established with $\mathrm{NaCl}$ in deionized water) on germination of 33 cultivars/seed lots of rough bluegrass in vitro. Fifty seeds of each cultivar/seed lot were placed on pre-moistened germination paper in petri dishes, sealed with parafilm, and placed in growth chambers with 12 -hours light/12-hours dark at $20 / 10{ }^{\circ} \mathrm{C}$, respectively. Germination was scored from 4 to 25 days after seed placement. Rough bluegrass germination rate varied among cultivars/seed lots, ranging from less than three seeds/day to nearly seven seeds/day. Salinity slowed rough bluegrass germination rate from about six seeds/day at $0 \mathrm{dS} \cdot \mathrm{m}^{-1}$ to five seeds/day at $5 \mathrm{dS} \cdot \mathrm{m}^{-1}$. Increasing salinity reduced early germination of some cultivar/seed lots more than that of others. Impact was substantial in three cultivar/seed lots, where early germination at $5.0 \mathrm{dS} \cdot \mathrm{m}^{-1}$ was less than $15 \%$ of that at $0 \mathrm{dS} \cdot \mathrm{m}^{-1}$. For most cultivar/seed lots, the reduction in early germination with salinity at $5.0 \mathrm{dS} \cdot \mathrm{m}^{-1}$ was about $50 \%$ of that at $0 \mathrm{dS} \cdot \mathrm{m}^{-1}$. Final germination was reduced only $3 \%$ by increasing salinity. In view of differences in germination rate and response to salinity among seed lots of rough bluegrass cultivars, we suggest the planting of multiple cultivars and seed lots of rough bluegrass to insure rapid establishment.
\end{abstract}

Rough bluegrass is the most commonly used species for overseeding bermudagrass in the coastal southeastern United States, where irrigation water is often saline. Overseeding of bermudagrass with rough bluegrass is performed annualy, therefore rapid germination and seedling establishment are critical to produce high quality turf. Salinity delays germination of many grasses (Harivandi et al., 1982; Lunt et al., 1961; Peacock and Dudeck, 1989), but the impact of salinity on rough bluegrass has received little study. Cultivar differences in salinity tolerance during germination have been demonstrated for Kentucky bluegrass (Poa pratensis L.) at salinity levels of 0.7 to $23.4 \mathrm{dS} \cdot \mathrm{m}^{-1}$ (Horst and Taylor, 1983), tall fescue (Festuca arundinacea Schreb.) at salinity levels of 0.7 to $23.4 \mathrm{dS} \cdot \mathrm{m}^{-1}$ (Horst and Beadle, 1984), perennial ryegrass (Lolium perenne L.) at salinity levels of 0 to 10,000 $\mathrm{mg} \cdot \mathrm{L}^{-1}\left(0\right.$ to $\approx 16 \mathrm{dS} \cdot \mathrm{m}^{-1}$ ) (Dudeck and Peacock, 1985), and creeping bentgrass (Agrostis sp.) at salinity levels of 0 to $16,000 \mathrm{mg} \cdot \mathrm{L}^{-1}$ ( 0 to $\approx 25 \mathrm{dS} \cdot \mathrm{m}^{-1}$ ) (McCarty and Dudeck, 1993). Seed lot differences in bentgrass germination rate and total germination as affected by

Received for publication 16 Oct. 2002. Accepted for publication 22 May 2003. Technical contribution no. 4877 of the South Carolina Agriculture and Forestry Research System, Clemson.

${ }^{1}$ Professor, Dept. of Entomology, Soils, and Plant Sciences. To whom requests for reprints should be addressed E-mail: jcmbrt@clemson.edu

${ }^{2}$ Professor, Dept. of Entomology, Soils, and Plant Sciences. salinity were suggested from results obtained in two separate experiments (McCarty and Dudeck, 1993), but not directly evaluated. In rough bluegrass, we have found cultivar differences in fungicide sensitivity (Camberato et al., 2001) and cultivar/seed lot variation in cold tolerance (Liu et al., 2001). In view of differences in response to fungicides and cold temperatures among cultivars and seed lots of rough bluegrass, we suspected differences in response to salinity. Our objective was to determine the effects of salinity on germination of commercially available rough bluegrass cultivars and seed lots.
Seed collection and storage. Seed from 33 rough bluegrass cultivars/seed lots (Table 1) were collected from golf course superintendents who had purchased commercially available seed. All but four were sold in the year we obtained them. Those four (J11-8-CY5-228, J6-8-Z1, J6-7-ST598, and J7-8-WP70) were all collected in 1998 and stored in our building with seasonally fluctuating temperatures between 21 and $27^{\circ} \mathrm{C}$. These cultivars/seed lots were examined in the 1999 experiment. Of those collected in the same year of sale, 12 were from that year of production and 17 were from the previous year's production. These seed were stored by the company or distributor with methods unknown to us, but typical of the industry. The sale of seed after 1 year of storage is not unusual with rough bluegrass. Storage on the golf course prior to our collection was no greater than four months and typically $<1$ month. During this time the seed were kept in buildings with no climate control. Once in our possession seed were transferred to zip-loc bags and kept at $25^{\circ} \mathrm{C}$ until use. Experiments were completed each year within 6 months of seed collection.

Of the 33 cultivar/seed lots, 20 were certified and seven were eligible for certification, but were not certified. The status of six cultivar/ seed lots was to the best of our knowledge neither certified nor eligible for certification. Five of the seven 'Sabre II' seed lots examined (not J6-9-ST638 and J6-9-ST615) were in this category. The other seed lot in this category was L68-0-TM14.

Tagged germination was provided for all but two of the cultivar/seed lots examined (Table 1). In our studies these two cultivar/seed lots, J68-LA629 and J79PA05, had a final germination with $0 \mathrm{dS} \cdot \mathrm{m}^{-1}$ of $95 \%$ and $93 \%$, respectively. All but three of the remaining 31 cultivar/seed lots had a final germination with $0 \mathrm{dS} \cdot \mathrm{m}^{-1}$ that exceeded their tagged germination. The three that had lower final germination than tagged germination were J6-9-Z38 (83\% vs. 85\%), J6-8-WP33 (87\% vs. 90\%), and J79PA66 (71\% vs. $85 \%$ ). The cultivar J79PA66 had a

Table 1. Cultivars/seed lots used to examine effects of salinity on rough bluegrass germination. Seed lots within each cultivar and year are listed in the order they appear in Fig. 1.

\begin{tabular}{|c|c|c|c|c|}
\hline \multirow{2}{*}{$\frac{\text { Cultivar }^{2}}{\text { Cypress }}$} & \multirow{2}{*}{$\begin{array}{c}\text { Year } \\
1999\end{array}$} & \multicolumn{3}{|c|}{--------------- Tag identification (tagged germination \%) ----------------- } \\
\hline & & J5-9-CY8-300-1 (90) & J5-9-CY8-299 (85) & J11-8-CY5-228 (90) \\
\hline & 2000 & J5-0-CY9-331 (85) & J5-9-CY8-299-1 (85) & J5-0-CY9-229 (85) \\
\hline \multirow[t]{2}{*}{ Laser } & 1999 & J6B-9-LA663 (85) & J6-8-LA629 (NP) & \\
\hline & 2000 & J6-9-LA405 (95) & J6-9-LA419 (85) & \\
\hline \multirow[t]{2}{*}{ Winterplay } & 1999 & J7-8-WP70 (92) & J6-8-WP33 (90) & \\
\hline & 2000 & J7-0-WP22 (85) & J6-9-WP71 (85) & J6-9-WP70 (85) \\
\hline \multirow[t]{2}{*}{ Darkhorse } & 1999 & J5-9-DH6-253-1 (85) & --- & --- \\
\hline & 2000 & J5-0-WD-339 (85) & J5-9-WD-326-1 (85) & \\
\hline \multirow[t]{3}{*}{ Sabre II } & 1999 & J6-7-ST598 (90) & J6-8-ST820 (85) & \\
\hline & 2000 & J6-9-ST615 (85) & J6-0-ST404 (85) & J6-9-ST638 (90) \\
\hline & & J6-9-ST648 (85) & J6-9-ST646 (90) & \\
\hline \multirow[t]{2}{*}{ Pro-Am } & 1999 & J79PA05 (NP) & --- & --- \\
\hline & 2000 & J79PA66 (85) & J79PA06 (80) & J79PA61-A (90) \\
\hline Fuzzy & 1999 & J6-9-Z38 (85) & $\mathrm{J} 6-8-\mathrm{Z1}(85)$ & \\
\hline Bariviera & 1999 & J78PT477 (85) & -- & --- \\
\hline Blend $^{\mathrm{x}}$ & 2000 & L68-0-TM14 (85) & --- & --- \\
\hline
\end{tabular}

${ }^{\mathrm{z}}$ Mention of a cultivar does not imply endorsement by Clemson Univ.

yTagged germination was not provided with these samples.

'The blend was reported to be comprised of equal amounts of 'Sabre II', 'Sabre', and 'Darkhorse'. 
test date of $7 / 00$ prior to our $10 / 00$ collection so the markedly lower final germination percentage was not expected. Except for this one cultivar/seed lot, the observed final germination percentage was nearly equivalent to or greater than the tagged germination percentage in 32 of 33 cultivar/seed lots. Seed purity ranged from $96.8 \%$ to $99.74 \%$ with most exceeding $98 \%$ (data not shown).

Experimental procedures. Fifty seed of each cultivar/seed lot were placed on premoistened \#38 regular weight germination circles (Anchor Paper Co., St. Paul, Minn.) in 9-cm diameter petri dishes and sealed with parafilm. Moistening solutions differing in salinity, $0,1.8,3.4$, or $5.0 \mathrm{dS} \cdot \mathrm{m}^{-1}$, were established in deionized water with $\mathrm{NaCl}$ at 0 , $0.88,1.75$, and $2.63 \mathrm{~g} \cdot \mathrm{L}^{-1}$. Irrigation water on South Carolina coastal golf courses typically range from 0.75 to $3.0 \mathrm{dS} \cdot \mathrm{m}^{-1}$. Seeds would be exposed to higher salinity due to evaporation. Petri dishes were placed in growth chambers with $12 \mathrm{~h}$ of light at $20^{\circ} \mathrm{C}$ and $12 \mathrm{~h}$ of darkness at $10^{\circ} \mathrm{C}$, providing conditions for rapid germination of vigorous seed lots. Light was provided with fluorescent lamps at $20 \mathrm{~W} / \mathrm{min}$ during the day. Experimental design was split block with salinity level as the main block and cultivar/seed lot completely randomized within each salinity level. There were nine and six replications of each treatment in 1999 and 2000 , respectively.

Salinity effects and cultivar/seed lot differences on germination rate were assessed by determining germination at 2 to 3 day intervals from 4 to $25 \mathrm{~d}$ after seeding. Seed was considered germinated if both a shoot and root were visible with $\times 10$ magnification. Final germination was determined when no additional seeds were germinated on two successive determinations. Germination rate was calculated by the method of Maguire (1962) which sums the number of new seedlings at each count divided by the number of days to each count $(\mathrm{t}) . \sum$ (no. new seedlings $\left.\div \mathrm{t}_{1}\right)+\left(\right.$ no. new seedlings $\left.\div \mathrm{t}_{2}\right)$ $+\left(\right.$ no. new seedlings $\left.\div \mathrm{t}_{\text {final }}\right)$.

Larger numbers indicate faster germination. A germination index (GI) was calculated by dividing $6 \mathrm{~d}$ germination with $5.0 \mathrm{dS} \cdot \mathrm{m}^{-1}$ by $6 \mathrm{~d}$ germination with $0 \mathrm{dS} \cdot \mathrm{m}^{-1}$. A GI of 1.0 indicates germination was just as rapid at $5.0 \mathrm{dS} \cdot \mathrm{m}^{-1}$ as at $0 \mathrm{dS} \cdot \mathrm{m}^{-1}$, and the cultivar/seed lot was salt tolerant. Indexes near 0 indicate salt sensitivity. All data were subjected to analysis of variance (ANOVA). Least significant difference (LSD) with a $P<0.05$ was used to identify treatment differences using the Statistical Analysis System (SAS Institute, 1985).

\section{Results and Discussion}

Rough bluegrass germination rate varied considerably among cultivars/seed lots (Table 2; Fig. 1, data shown averaged over salinity levels of $0,1.8,3.4$, and $5.0 \mathrm{dS} \cdot \mathrm{m}^{-1}$ ). Four or more seed lots of five different cultivars were examined over the 2-year study. Of these, only 'Laser' showed consistent germination rate among seed lots. All four seed lots of this cultivar were among the most rapid examined. Differences in germination rate among seed
Table 2. Analysis of variance for cultivar/seed lot and salinity effects on rough bluegrass germination rate, final germination percentage, and germination index.

\begin{tabular}{|c|c|c|c|c|c|c|}
\hline \multirow{2}{*}{$\begin{array}{l}\text { Source of } \\
\text { variation }\end{array}$} & \multicolumn{2}{|c|}{ Germination rate $^{z}$} & \multicolumn{2}{|c|}{ Final germination } & \multicolumn{2}{|c|}{ Germination index $x^{y}$} \\
\hline & 1999 & 2000 & 1999 & 2000 & 1999 & 2000 \\
\hline & & & $\begin{array}{r}\text { evel of s } \\
0.0001\end{array}$ & $\begin{array}{c}\text { ificance } \\
0.0001\end{array}$ & ----- & ----- \\
\hline Cultivar/seed & 0.0001 & 0.0001 & 0.0001 & 0.0001 & 0.0001 & 0.0001 \\
\hline Salinity * Cult./lot & 0.26 & 0.79 & 0.28 & 0.53 & ------ & ------ \\
\hline
\end{tabular}

${ }^{2}$ Rate $=\sum$ (no. new seedlings $\left.\div \mathrm{t}_{1}\right)+\left(\right.$ no. new seedlings $\left.\div \mathrm{t}_{2}\right)+\left(\right.$ no. new seedlings $\left.\div \mathrm{t}_{\text {final }}\right)$. y Index $=$ Germination at $6 \mathrm{~d}$ with $5.0 \mathrm{dS} \cdot \mathrm{m}^{-1}$ divided by germination at $6 \mathrm{~d}$ with $0 \mathrm{dS} \cdot \mathrm{m}^{-1}$.

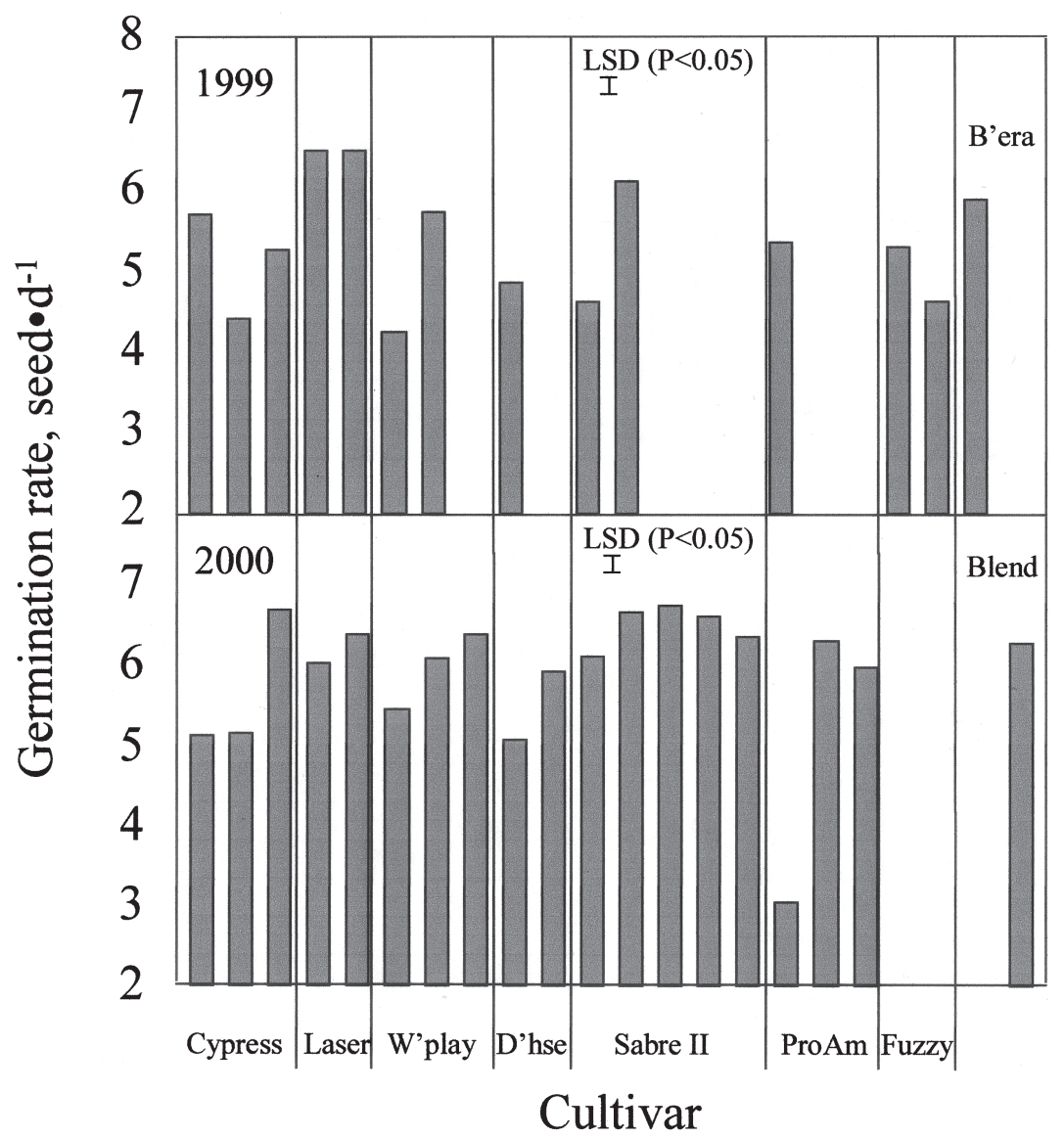

Fig. 1. Rough bluegrass germination rate for 14 cultivars/seed lots in 1999 and 19 cultivars/seed lots in 2000 averaged over salinity levels of $0,1.8,3.4$, or $5.0 \mathrm{dS} \cdot \mathrm{m}^{-1}$. Seed lots within a cultivar and year are shown in the order they are listed in Table 1 . Germination rate $=\sum$ (no. new seedlings $\left.\div \mathrm{t}_{1}\right)+($ no. new seedlings $\left.\div \mathrm{t}_{2}\right)+\left(\right.$ no. new seedlings $\left.\div \mathrm{t}_{\text {fina }}\right)$. The least significant difference $(P<0.05)$ for comparing cultivars/seed lots within each year was 0.25 in 1999 and 0.26 in 2000

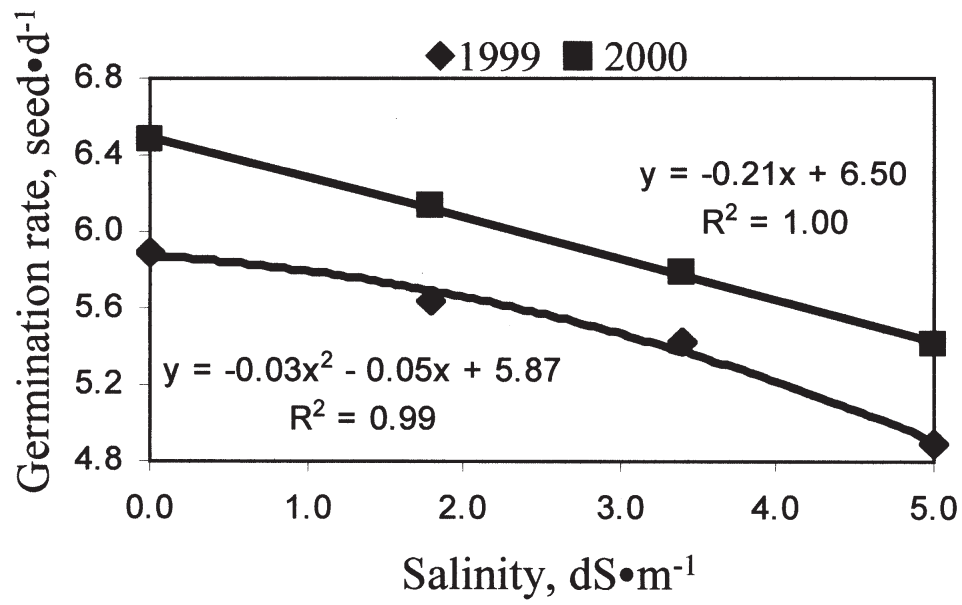

Fig. 2. Rough bluegrass germination rate at salinity levels of $0,1.8,3.4$, and $5.0 \mathrm{dS} \cdot \mathrm{m}^{-1}$ averaged for 14 cultivars/seed lots in 1999 and 19 cultivars/seed lots in 2000. Germination rate $=\Sigma$ (no. new seedlings $\left.\div \mathrm{t}_{1}\right)+\left(\right.$ no. new seedlings $\left.\div \mathrm{t}_{2}\right)+\left(\right.$ no. new seedlings $\left.\div \mathrm{t}_{\text {final }}\right)$. 
lots of the other four cultivars ('Cypress', 'Winterplay', 'Sabre II', and 'ProAm') were as great as $100 \%$ ('ProAm' in 2000), but more typically $20 \%$ to $30 \%$.

Salinity reduced germination rate of all rough bluegrass cultivars/seed lots, and each level of salinity slowed germination (Table 2; Fig. 2, data shown averaged over all cultivars/ seed lots for each year). The response was linear in 2000 and quadratic in 1999. The germination index was calculated to facilitate comparisons among cultivars/seed lots in sensitivity to salinity. Eight of fourteen cultivars/ seed lots examined in 1999 had a GI between 0.37 and 0.57 (Table 2; Fig. 3), meaning early germination at $5.0 \mathrm{dS} \cdot \mathrm{m}^{-1}$ was about half that at $0 \mathrm{dS} \cdot \mathrm{m}^{-1}$. One seed lot of 'Winterplay' was extremely sensitive to salinity with a GI of 0.12 . The GI (0.41) of the other 'Winterplay' seed lot was not statistically different from that of the majority of other cultivars. A seed lot of 'Laser', one of 'Sabre II', and two seed lots of 'Fuzzy' showed superior salt tolerance to some seed lots of the more salt sensitive cultivars, but did not differ from other seed lots of the same cultivar. Most cultivars/seed lots tested in 2000 had a GI between 0.33 and 0.52 (Fig. 3). The salt tolerance of two seed lots of 'Sabre II' exceeded this range, but did not differ from the three other 'Sabre II' seed lots examined. Seed lots of 'ProAm' exhibited the greatest GI variability of any cultivar. One 'ProAm' seed lot was the least salt tolerant of any seed lot examined $(\mathrm{GI}=0.10)$, another approached the most salt tolerant $(\mathrm{GI}=0.54)$, and a third was intermediate $(\mathrm{GI}=0.36)$. No obvious reason could be found to explain the differences among these seed lots of 'ProAm'. All three seed lots were produced by the same company in the 1999 growing season, had July or Aug. 2000 germination test dates, and were sold by the same distributor. 'Darkhorse' also showed substantial seed lot variability with a GI of 0.14 and 0.42 for the two seed lots tested. Germination of rough bluegrass cultivars has been shown to be differentially sensitive to fungicides (Camberato et al., 2001) and low temperatures (Liu et al., 2001). Seed lot differences in low temperature sensitivity were also demonstrated (Liu et al., 2001). McCarty and Dudeck (1993) suspected seed lot differences in bentgrass germination sensitivity to salinity in successive runs of an experiment, but did not directly test this hypothesis.

Although increasing salinity from 0 to $5.0 \mathrm{dS} \cdot \mathrm{m}^{-1}$ substantially reduced the germination rate of rough bluegrass (Fig. 2), salinity reduced final germination $<3 \%$ (Table 2; Fig. 4). This result is in accord with previous research which found that moderate levels of salinity $\left(\approx 5.0 \mathrm{dS} \cdot \mathrm{m}^{-1}\right.$ or less) typically slow germination, but do not substantially reduce final germination in crop plants (Ayers, 1952; Pearson, et al., 1966; Miyamoto, 1989), or in grasses. Final germination of a perennial ryegrass cultivar was unaffected by salt concentration up to $5000 \mathrm{mg} \cdot \mathrm{L}^{-1}\left(\approx 8 \mathrm{dS} \cdot \mathrm{m}^{-1}\right)$, but germination rate was slowed (Dudeck et al., 1986). An additional $1.2 \mathrm{~d}$ was necessary to attain $50 \%$ germination with salt at 5000 $\mathrm{mg} \cdot \mathrm{L}^{-1}$ in comparison to the no salt control.
Carpetgrass (Axonopus affinis Chase) and centipedegrass [Eremochloa ophiuroides (Munro) Hack.] germination rate was slowed by salt concentrations up to $5800 \mathrm{mg} \cdot \mathrm{L}^{-1}(\approx 9$ $\left.\mathrm{dS} \cdot \mathrm{m}^{-1}\right)$, but final germination was unaffected (Peacock and Dudeck, 1989). In the same study, final germination of two cultivars of bahiagrass (Paspalum notatum Flugge.) was decreased only $10 \%$ by $5800 \mathrm{mg} \cdot \mathrm{L}^{-1}$. Soil salinity of $4 \mathrm{dS} \cdot \mathrm{m}^{-1}$ had no impact on final germination of three forage grasses but salinity of $10 \mathrm{dS} \cdot \mathrm{m}^{-1}$ reduced final germination to $68 \%$ from the control at $74 \%$ (Miller and Chapman, 1978).

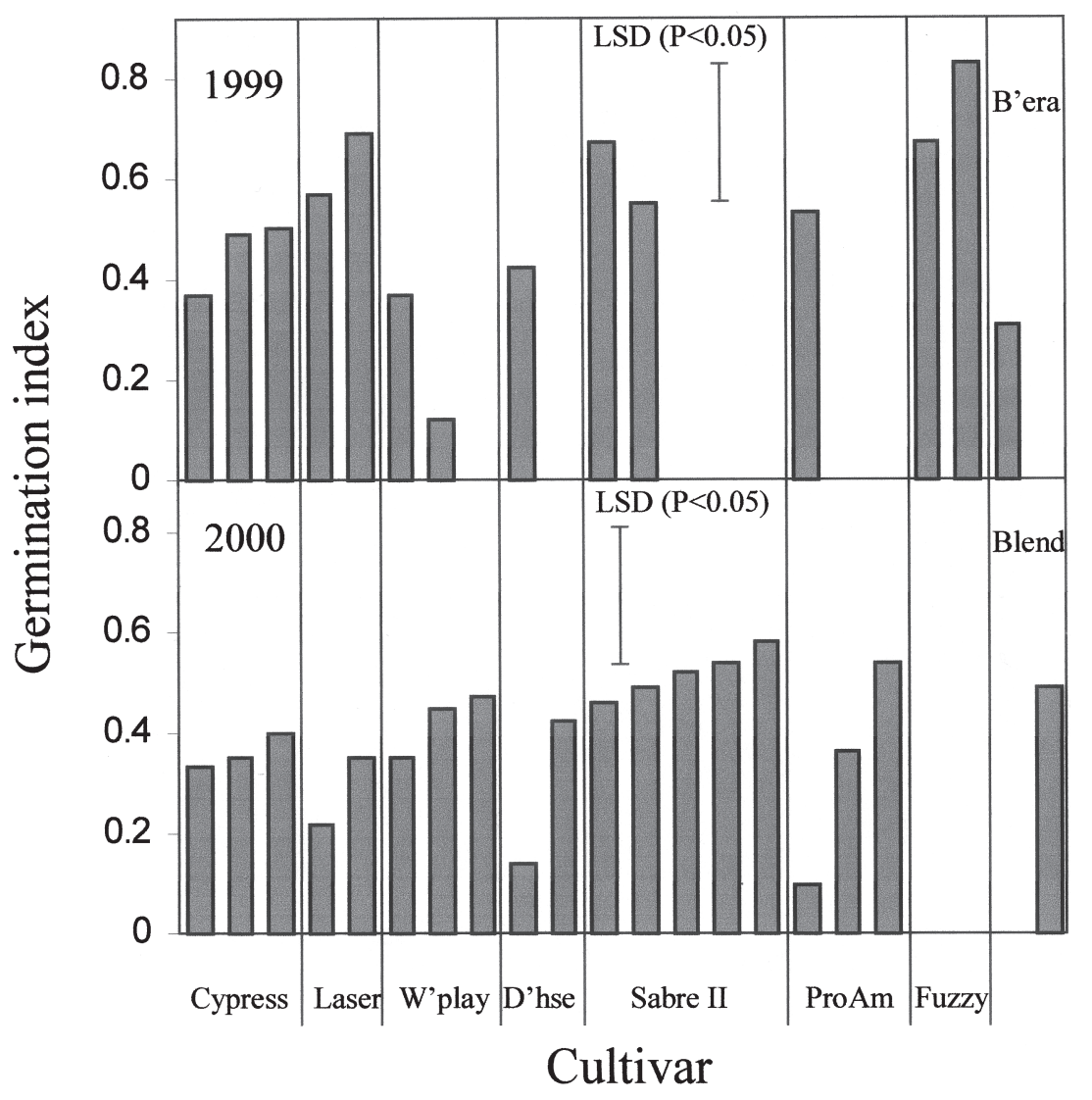

Fig. 3. Rough bluegrass germination index for 14 cultivars/seed lots in 1999 and 19 cultivars/seed lots in 2000. Seed lots within a cultivar and year are shown in the order they are listed in Table 1. Germination index $=$ germination at $6 \mathrm{~d}$ with $5.0 \mathrm{dS} \cdot \mathrm{m}^{-1}$ divided by germination at $6 \mathrm{~d}$ with $0 \mathrm{dS} \cdot \mathrm{m}^{-1}$. The least significant difference (LSD) $(P<0.05)$ for comparing cultivars/seed lots within each year was 0.27 in 1999 and 0.23 in 2000.

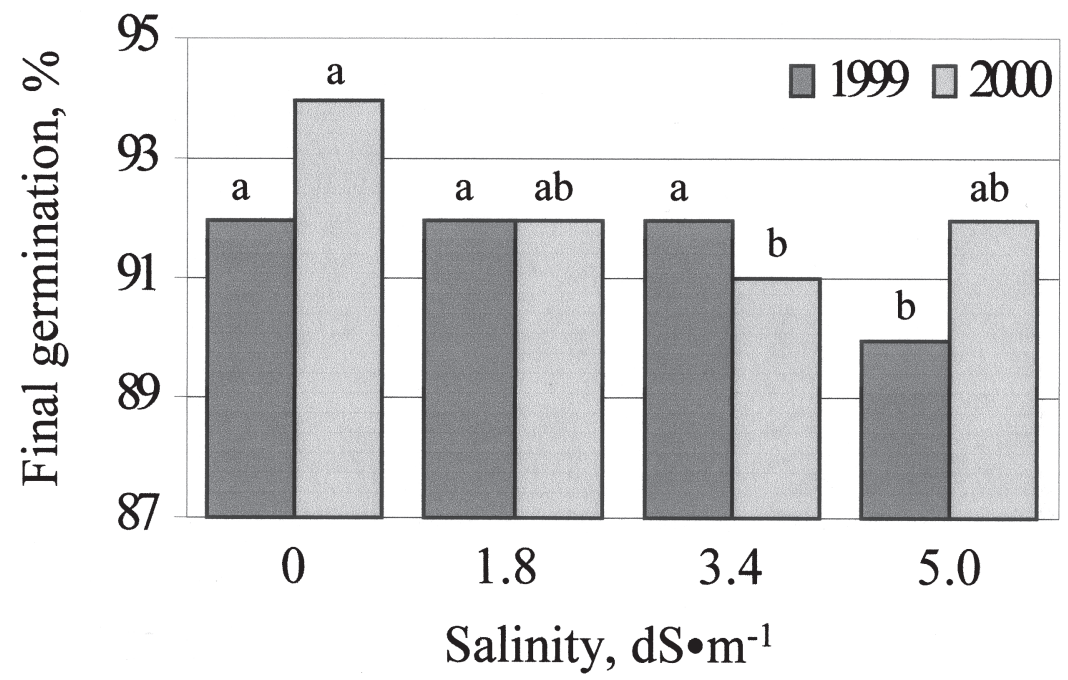

Fig. 4. Final rough bluegrass germination at salinity levels of $0,1.8,3.4$, and $5.0 \mathrm{dS} \cdot \mathrm{m}^{-1}$ averaged for 14 cultivars/seed lots in 1999 and 19 cultivars/seed lots in 2000. Columns within a year topped by the same letter do not differ as assessed by least significant difference $(P<0.05)$. 


\section{Conclusion}

Germination rate differed by as much as $100 \%$ among rough bluegrass cultivars/seed lots, ranging from less than three seeds/day to nearly seven seeds/day, although differences of 20 to $30 \%$ were more typical. Salinity slowed rough bluegrass germination rate from about six seed/day at $0 \mathrm{dS} \cdot \mathrm{m}^{-1}$ to five seed/day at $5 \mathrm{dS} \cdot \mathrm{m}^{-1}$. Increasing salinity reduced early germination of some cultivar/seed lots more than that of others. Impact was substantial in three cultivar/seed lots where early germination at $5.0 \mathrm{dS} \cdot \mathrm{m}^{-1}$ was $<15 \%$ that at $0 \mathrm{dS} \cdot \mathrm{m}^{-1}$. For most cultivar/seed lots, the reduction in early germination with salinity at $5.0 \mathrm{dS} \cdot \mathrm{m}^{-1}$ was only about half that at $0 \mathrm{dS} \cdot \mathrm{m}^{-1}$. Final germination was reduced only $3 \%$ by increasing salinity. Inconsistent germination rate among seed lots of rough bluegrass cultivars renders selection of a particular cultivar based on past experience, unwise. We recommend the planting of multiple cultivars and seed lots of rough bluegrass, particularly when saline irrigation water is utilized.

\section{Literature Cited}

Ayers, A.D. 1952. Seed germination as affected by soil moisture and salinity. Agron. J. 44: 82-84.

Camberato, J.J., S.B. Martin, and A.V. Turner. 2001 Fungicides affect rough bluegrass germination and seedling development. Intl. Turfgrass Soc. Res. J. 9:649-654.

Dudeck, A.E., and C.H. Peacock. 1985. Salinity effects on perennial ryegrass germination. HortScience 20:268-269.

Dudeck, A.E., C.H. Peacock, and T.J. Sheehan. 1986. An evaluation of the germination media for turfgrass salinity studies. J. Amer. Soc. Hort. Sci. 111:170-173

Harivandi, M.A., J.D. Butler, and P.M. Soltanpour. 1982. Salt influence on germination and seedling survival of six cool season turfgrass species. Commun. Soil Sci. Plant Anal. 13:519-529.

Horst, G.L., and N.B. Beadle. 1984. Salinity affects germination and growth of tall fescue cultivars. J. Amer. Soc. Hort. Sci. 109:419-422.

Horst, G.L., and R.M. Taylor. 1983. Germination and initial growth of Kentucky bluegrass in soluble salts. Agron. J. 75:679-681.

Liu, Chunhua, J.J. Camberato, S. Bruce Martin, and Amy Turner. 2001. Rough bluegrass germina- tion varies with temperature and cultivar/seed lot. HortScience 36:153-156.

Lunt, O.R., V.B. Youngner, and J.J. Oertli. 1961. Salinity tolerance of five turfgrass varieties. Agron J. 53:247-249.

Maguire, J.D. 1962. Speed of germination - Aid in selection and evaluation for seedling emergence and vigor. Crop Sci. 2:176-177.

McCarty, L.B., and A.E. Dudeck. 1993. Salinity effects on bentgrass germination. HortScience 28:15-17.

Miller, T.R., and S.R. Chapman. 1978. Germination responses of three forage grasses to different concentrations of six salts. J. Range Mgt. 31: 123-124.

Miyamoto, S. 1989. Salt effects on germination, emergence, and seedling mortality of onion. Agron. J. 81:202-207.

Peacock, C.H., and A.E. Dudeck. 1989. Influence of salinity on warm season turfgrass germination. p. 229-231. Proc. $6^{\text {th }}$ Intl.Turfgrass Res. Conf., Tokyo, 31 July-5 Aug.

Pearson, G.A., A.D. Ayers, and D.L. Eberhard. 1966. Relative salt tolerance of rice during germination and early seed development. Soil Sci. 102:151-156.

SAS Institute, Inc. 1985. SAS user's guide: Statistics. $5^{\text {th }}$ ed. SAS Inst. Cary, N.C. 